\title{
(2) OPEN ACCESS \\ Influence of individual, illness and environmental factors on place of death among people with neurodegenerative diseases: a retrospective, observational, comparative cohort study
}

\author{
Richard Nicholas, ${ }^{1}$ Emma Nicholas, ${ }^{1}$ Mike Hannides, ${ }^{1}$ Vishal Gautam, ${ }^{1}$ \\ Tim Friede (D) , Jonathan Koffman (D) ${ }^{3}$
}

- Additional supplemental material is published online only. To view, please visit the journal online (http://dx.doi. org/10.1136/bmjspcare-2021 003105).

For numbered affiliations see end of article.

\section{Correspondence to}

Dr Jonathan Koffman, Department of Palliative Care, Policy and Rehabiltation, Florence Nightingale Faculty of Nursing, Midwifery and Palliative Care, King's College London, London, UK; jonathan.koffman@kcl.ac.uk

Received 7 April 2021 Accepted 11 July 2021

\section{Check for updates}

(C) Author(s) (or their employer(s)) 2021. Re-use permitted under CC BY-NC. No commercial re-use. See rights and permissions. Published by BMJ.

\footnotetext{
To cite: Nicholas $R$, Nicholas E, Hannides M, et al. BMJ Supportive \& Palliative Care Epub ahead of print: [please include Day Month Year]. doi:10.1136/ bmjspcare-2021-003105
}

\section{ABSTRACT}

Background In long-term neurological conditions, location of death is poorly understood but is seen as a marker of quality of dying.

Objective To examine individual, illness and environmental factors on place of death among people with multiple sclerosis (MS) and Parkinson's disease (PD) in isolation or in combination and compare them with people without either condition.

Methods Retrospective, observational, comparative cohort study of 582 people with MS, 579 people with PD and 95 controls from UK Multiple Sclerosis and Parkinson's Disease Tissue Bank. A subset of people with MS and PD were selected for analysis of individual clinical encounters 2 years before death and further subset of all groups for analysis of impact of advance care planning (ACP) and recognition of dying.

Results People with MS died more often $(50.8 \%)$ in hospital than those with PD (35.3\%). Examining individual clinical encounters over 2 years (4931 encounters) identified increased contact with services 12 months before death $(F(1,58)=69.71, \mathrm{p}<0.0001)$ but was not associated with non-hospital deaths ( $F(1$, 58) $=1.001, p=0.321)$. The presence of ACPs and recognition of dying were high among people with MS and PD and both associated with a non-hospital death. ACPs were more likely to prevent hospital deaths when initiated by general practitioners (GPs) compared with other professional groups $\left(\chi^{2}=68.77, p=0.0007\right)$.

Conclusions For people with MS and PD, ACPS contribute to reducing dying in hospital. ACPs

\section{Key messages}

\section{What was already known?}

- Most people prefer to die at home. Factors influencing location of death include a person's illness (an 'individual' factor) and 'environmental-related' considerations.

- Advance care planning (ACP) is an 'individual-oriented' factor that influences health-related outcomes for people living with life-limiting conditions. In multiple sclerosis (MS) and Parkinson's disease (PD) the effect of these factors in facilitating home deaths remains unknown.

What are the new findings?

- Possessing an ACP (individual factor) contributed to dying at home for people with MS and PD.

- General practitioners represented a key factor in initiating conversations on ACP with people with MS and PD and in coordinating a patient's care with their family. This made it possible for care to take place where they wanted.

\section{Clinical significance}

- Professionals working in primary care effectively recognise the final phase of people living with long-term neurological conditions and engaging in difficult conversations that include ACP to realise care preferences, including location of death.

appear to be most effective when facilitated by GPs underlining the importance of primary care involvement in delivering holistic care at the end of life. 


\section{INTRODUCTION}

Location of death is an indicator of the quality of end-of-life care with up to four-fifths of the general population expressing a wish to die in their usual place of care, normally their own home. ${ }^{12}$ Most deaths continue to occur in institutional settings ${ }^{34}$ and there is evidence that quality of end-of-life care in institutions is less favourable than at home. ${ }^{1}$

In the context of long-term neurological conditions, ${ }^{5}$ including multiple sclerosis (MS) and Parkinson's disease (PD), the usual place of care can differ as increasing impairment and a 'progressive dwindling' disease trajectory, where disability and frailty accumulate chronically. This makes home care and dying at home difficult. ${ }^{67}$ In the UK, based on death certification, the rates of death in hospital for people with longterm neurological conditions are higher compared with those with cancer diagnoses. ${ }^{8}$ However, there is considerable variation depending on the condition and this rate is reflected in the MS population where $55.8 \%$ die in hospital, ${ }^{9}$ whereas for those with PD the rate of hospital death in the UK varies from $40 \%$ to $43.4 \% \%^{910}$ and is below that of the general population.

Factors that influence the location of death have been postulated to include a person's illness, in addition to individual and environmental-related considerations. ${ }^{11}$ Advance care planning (ACP) has been shown as representing an 'individual' oriented factor that can positively influence some health-related outcomes for people living with life-limiting conditions and their families. ${ }^{12-14}$ For this paper, we understand ACP as a process that 'enables individuals to define goals and preferences for future medical treatment and care, to discuss these goals and preferences with family and healthcare providers, and to record and review these preferences if appropriate'. 15 This can include sharing wishes on preferences for location of care and eventual death. ACP has been endorsed in the UK's 2021 national policy document 'Ambitions for Palliative and End of Life Care' ${ }^{16}$ in many countries in Europe, ${ }^{17}$ the USA, $^{18}$ Australia ${ }^{19}$ and Taiwan, ${ }^{20}$ among others. There is some evidence that advance care plans can reduce healthcare costs. $^{21} 22$ Most recently, ACP has been widely endorsed during the COVID-19 pandemic as a means to facilitate people's preferences regarding future medical care under challenging conditions. ${ }^{23-25}$

The potential benefits of ACP for people severely affected by neurological conditions and their families can include providing important opportunities for discussion of diagnosis and prognosis so care is aligned with their preferences, improving symptom discussions, treatment adherence and reduced misunderstandings and conflict between medical staff and families. $^{26}$

The UK Multiple Sclerosis and Parkinson's Disease Tissue Bank (UK MS PD TB) is a national collection of central nervous system tissue samples donated after death by individuals with MS, PD and related neuroinflammatory and neurodegenerative conditions. $^{27}$ The donor schemes are community based and for those with MS has been demonstrated to closely reflect the whole UK MS population. ${ }^{28}$ The UK MS PD TB offers a unique opportunity to study these two neurodegenerative diseases, their previous health encounters, and the type, content and frequency of conversations they had, with whom and to what effect. The tissue bank fortuitously also includes a population of those who died without evidence of neurodegenerative diseases and who were recruited under similar conditions. They typically include family members of those who died from neurodegenerative disease members of the public. Donors sign up to the UK MS PD TB when alive and are followed through until death when their associated clinical notes are also available for analysis. This provides a unique opportunity to examine a population-based sample concerning the characteristics of these individuals and the circumstances of their death, particularly given that there is evidence that approximately 35\% of people with MS do not have their disease mentioned on their death certificate. ${ }^{7}$ Additionally, the UK MS PD TB also enables the identification and examination of all healthcare professional (HCP), patient and family interactions before an individual's death.

In this paper, we report a population-based observational study of deaths among people living with MS and PD to examine their location of death, the factors associated with home deaths either in isolation or in combination and compare them with the outcomes of people without either condition, referred to as the 'control population'. The factors we focused on drawing on Gomes and Higginson's theoretical model ${ }^{11}$ associated with home death presented in box 1. For our study, they include factors associated with the person's illness; 'individual factors' that comprise the personal contextual components, for example, the presence of

\section{Box 1 Factors associated with home death ${ }^{11}$}

- Factors related to illness-clinical changes that occur because of illness. These relate to what caused the disruption in patients' lives (the illness) and symbolise a threat to patients' continuity.

- Individual factors - account for the maintenance of patients' individuality, comprising demographic variables (relatively stable and unchangeable characteristics defining the patients' identity) and personal variables (which reflect the patients' beliefs, wishes and inner resources to cope with their illness).

- Environmental factors - contextual determinants that comprise variables related to the healthcare input available and received by the patients and carers, the patients' social support networks and macrosocial factors (defined as determinants at a group or system level related to a certain sociohistorical moment, political approach and culture defining a wide group of people). 
an advance care plan; and 'environmental factors' that include the involvement of healthcare.

\section{METHODS \\ Design}

This study involved a population-based, retrospective, observational, comparative cohort study making use of the UK MS PD TB. The UK MS Tissue Bank originated at Imperial College London in 1998 and the Parkinson's Disease Tissue Bank later in 2002. While the 'banks' are separate entities they both comprise control cases. For this study, the banks and their control cases have been combined. Two pilot studies were initially undertaken in MS (February to May 2017) and then in PD (February to April 2018) to examine the feasibility of addressing the study questions. In this paper, we have examined the records of people with MS on the tissue bank database from January 1998 to September 2016, those with PD from January 2002 to August 2018 and the control population from January 1998 to August 2018.

\section{Case eligibility criteria and data extraction}

Cases for in-depth analysis of clinical encounters were selected where complete general practitioner (GP) notes were available, starting from the most recent case available until 30 cases were collected from each disease group. Each case selection was agreed on by two investigators (EN and RN for MS; $\mathrm{MH}$ and EN for PD). Eligibility criteria included the requirement for a full set of complete GP records for at least 2 years before an individual's death. In this group, each encounter with health and social care services was recorded and classified as being provided by the community (community nursing), primary (GP) or secondary care (hospital). Data were scrutinised by a second investigator. After statistical input (TF), a further subgroup analysis looked for mention in clinical notes of 'advance care planning', 'ACP' and 'advanced directive', in addition to elements associated with ACP, for example, 'just in case'/anticipatory prescribed medicines. We also looked for instances of recognition of dying, present when the words 'dying' or 'end of life care' were mentioned in notes from a similar number of MS and PD subjects to the number of controls $(n=95)$ where available.

\section{Analysis}

The objectives and analysis plan were prespecified for the MS study and replicated for PD (refer to online supplemental file 1). Statistical analysis was performed using the paired t-test, two-way analysis of variance (ANOVA), Kolmogorov-Smirnov test (GraphPad Prism V.7.02, September 2016: www.graphpad.com), $\chi^{2}$ test and Fisher's exact test (VassarStats: www. vassarstats.net accessed 28 November 2020) where appropriate. Modelling the dependence of the two primary outcomes on the covariates was performed using logistic regression models using R (V.3.4.2: 28 September 2017). Covariates were described as HRs and are reported with 95\% CIs and $\mathrm{p}$ values testing the null hypothesis of no effect $(H R=1)$. Data are presented as ratios, percentages and means $\pm \mathrm{SD}$ where appropriate.

\section{RESULTS}

\section{Characteristics of the UK Tissue Bank populations and} location of death

In total, 1256 deaths were considered in this analysis and comprised 582 people with MS, 579 people with PD and 95 controls (table 1). In an initial pilot to understand how healthcare support influenced the place of death, we studied in detail a group of 30 people with MS and 30 people with $\mathrm{PD}$, selected using

\begin{tabular}{|c|c|c|c|c|c|c|}
\hline & & $\begin{array}{l}\text { Control } \\
\text { population } \\
(\mathrm{n}=95)\end{array}$ & $\begin{array}{l}\text { Multiple sclerosis } \\
(\mathrm{n}=582)\end{array}$ & $\begin{array}{l}\text { Multiple sclerosis } \\
\text { pilot }(n=30)\end{array}$ & $\begin{array}{l}\text { Parkinson's disease } \\
(\mathrm{n}=579)\end{array}$ & $\begin{array}{l}\text { Parkinson's } \\
\text { disease pilot } \\
(n=30)\end{array}$ \\
\hline \multicolumn{2}{|l|}{ Age (mean $\pm S D)$} & $79.3 \pm 12.0$ & $63.8 \pm 12.7$ & $65.1 \pm 12.1$ & $79.7 \pm 8.2$ & $77.2 \pm 8.4$ \\
\hline \multicolumn{2}{|l|}{ Female (\%) } & $41(47.1)$ & $379(70.4)$ & $21(70)$ & $241(41.6)$ & $6(20)$ \\
\hline \multicolumn{2}{|c|}{ Disease length (mean $\pm S D$ ), missing } & - & $30.4 \pm 12.2,79$ & $23.7 \pm 11.5,0$ & $12.5 \pm 6.2,236$ & $10.4 \pm 4.2,0$ \\
\hline \multirow{5}{*}{$\begin{array}{l}\text { Death trajectory } \\
\text { (\% excluding } \\
\text { missing data) }\end{array}$} & Missing & 21 & 0 & 0 & 233 & 0 \\
\hline & Clear transition & $30(40)$ & $59(10.1)$ & $3(10)$ & $24(6.9)$ & \\
\hline & Acute exacerbation & $5(6.8)$ & $18(3.1)$ & - & $8(2.3)$ & - \\
\hline & Sudden & $32(43.2)$ & $76(13.1)$ & - & $4(1.2)$ & - \\
\hline & Progressive dwindling & $7(9.5)$ & $429(73.7)$ & $27(90)$ & $310(89.6)$ & $100(100)$ \\
\hline \multirow{6}{*}{$\begin{array}{l}\text { Place of death } \\
\text { (\% excluding } \\
\text { missing data) }\end{array}$} & Missing & 8 & 47 & 0 & 236 & 0 \\
\hline & Home & $28(32.2)$ & $100(18.7)$ & $4(13.3)$ & $40(11.6)$ & $5(16.7)$ \\
\hline & Hospital & $37(42.5)$ & $272(50.8)$ & $16(53.3)$ & $122(35.3)$ & $11(36.7)$ \\
\hline & Care home & $16(18.4)$ & $137(25.6)$ & $7(23.3)$ & $183(52.9)$ & $14(46.7)$ \\
\hline & Hospice & $6(6.9)$ & $24(4.5)$ & $3(10)$ & $1(0.3)$ & - \\
\hline & $\begin{array}{l}\text { Psychiatric/convents/ } \\
\text { prisons }\end{array}$ & - & $2(0.4)$ & - & - & - \\
\hline
\end{tabular}


the same prespecified criteria. To focus on the influence of ACP and the recognition of dying in comparison to controls, an analysis was completed for those in the control, MS and PD groups based on the number of available controls.

People with MS typically died at a younger age and there were more females compared with those with people with PD and the controls. There was a difference between populations in terms of the death trajectory experienced. In both the long-term neurological conditions, we identified a higher rate of 'progressive dwindling' specifically, $73.7 \%$ among those with MS versus $9.5 \%$ among controls $\left(\chi^{2}=31.19, \mathrm{p}<0.0001\right)$ and also when comparing controls with those with PD $\left(89.6 \%, \chi^{2}=211.5, p<0.0001\right)$. Furthermore, 'progressive dwindling' was identified as being higher among those with PD than MS $\left(\chi^{2}=13.76\right.$, $\mathrm{p}<0.0002$ ).

In the control population, 37/95 (42.5\%) individuals died in hospital, a similar proportion to the expected rate in the UK. Significantly fewer people with PD $(\mathrm{n}=122,35.3 \%)$ died in hospital than those with MS $(\mathrm{n}=272,51.1 \%)\left(\chi^{2}=19.71, \mathrm{p}<0.0001\right)$. More people with PD died in nursing homes compared with those with MS $(52.9 \%$ vs $25.6 \%) \quad\left(\chi^{2}=69.46, p<0.0001\right)$ and controls $(18.4 \%) \quad\left(\chi^{2}=34.12, \quad \mathrm{p}<0.0001\right)$. However, significantly fewer people with PD $(11.6 \%$, $\left.\chi^{2}=21.95, \mathrm{p}<0.0001\right)$ and those with MS $(18.7 \%$, $\left.\chi^{2}=8.33, \mathrm{p}=0.0039\right)$ died in their own residence compared with controls (32.2\%). Furthermore, just one $(0.3 \%)$ person with PD died in hospice compared with controls $(6.9 \%$, Fisher's exact test, two sided, $\mathrm{p}=0.0004)$ and people with MS (4.5\%, Fisher's exact test, two sided, $\mathrm{p}=0.0005$ ).

\section{Individual illness and demographic factors related to the location of death}

To identify to what extent factors associated with the person's illness and their 'individual' factors contributed to understanding where they died, we made use of the following variables-disease type, age of death, sex and disease trajectory-and performed multivariate modelling to examine two outcomes-death in hospital or death at home. While death in hospital was common, we identified that factors associated with a hospital death included older age of death (HR 95\% CI (upper, lower), $\mathrm{p}=0.996$ (0.993, 0.998), $\mathrm{p}=0.00019$ ) and being less likely to experience a progressive dwindling disease course $(0.969(0.939,1.000), p=0.051)$. However, when taken together, they only explained $1.6 \%$ of why a person died in hospital $(\mathrm{df}=950$, adjusted $\mathrm{R}^{2}=0.0157, \mathrm{p}=0.000197$ ). For home deaths, we identified that older age and not having MS or PD were significant factors associated with home death. However, taken together, they accounted for only $2.6 \%$ of why a person died at home $(\mathrm{df}=964$, adjusted $\mathrm{R}^{2}=0.0256, \mathrm{p}=0.009$ ).

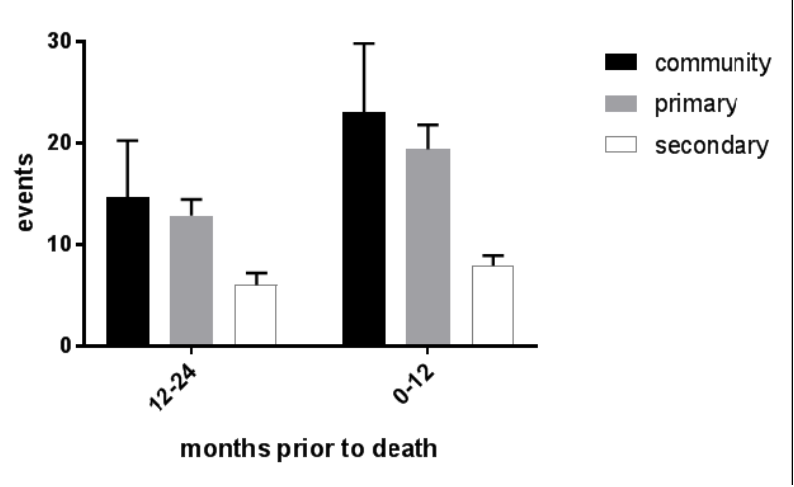

Figure 1 Type and number of clinical encounters prior to death for people with multiple sclerosis.

\section{Environmental factors and location of death}

We investigated the contribution of environmental factors and their impact on the location of death, logging the type of clinical encounters people with MS $(n=30)$ and PD $(n=30)$ accessed in the 2 years before death. There were 4931 clinical encounters in total (2516 events for people with MS; 2421 for people with PD). Overall, 1695 clinical encounters (34.3\%) involved community care, 2205 clinical encounters (44.7\%) involved primary care and 1037 clinical encounters $(21 \%)$ involved secondary care. For both the MS and PD, the number of clinical encounters increased from time point $12-24$ months to time point $0-12$ months before death (two-way repeated measures ANOVA, $F(1,58)=69.71, \mathrm{p}<0.0001)$. However, there was no overall difference between the conditions (two-way repeated measures ANOVA, $F(1$, $58)=1.035, \mathrm{p}=0.313)$.

We examined the type and number of clinical encounters separately to determine to what extent there were differences between MS and PD beyond an increase between 12-24 months and 0-12 months. In MS (figure 1), although there was an increase in clinical encounters in the $0-12$ months before death compared with 12-24 months (two-way repeated measures ANOVA, $F(1,87)=15.93, \mathrm{p}=0.0001)$, there were no difference between the community, primary and secondary care encounters (two-way repeated measures ANOVA, $F(2,87)=2.969, \mathrm{p}=0.057)$. For people with $\mathrm{PD}$, there was, however, a difference between $12-24$ and $0-12$ months (two-way repeated measures ANOVA, $F(1,87)=28.12, \mathrm{p}<0.0001)$ as with MS but also between the types of interventions (two-way repeated measures ANOVA, $F(2,87)=17.63$, $\mathrm{p}<0.0001$ ) (figure 2). Primary care increased above community care at 12-24 months (Tukey's multiple comparisons, mean difference 95\% CI (upper, lower) $-11.1(-16.82,-5.82), \mathrm{p}<0.0001)$ and at $0-12$ months $(-11.4(-17.12,-5.682), \mathrm{p}<0.0001)$. Moreover, primary care encounters increased above secondary care encounters at 12-24 months $(8.133$ $(2.415,13.85), \mathrm{p}=0.0027)$ and at $0-12$ months 


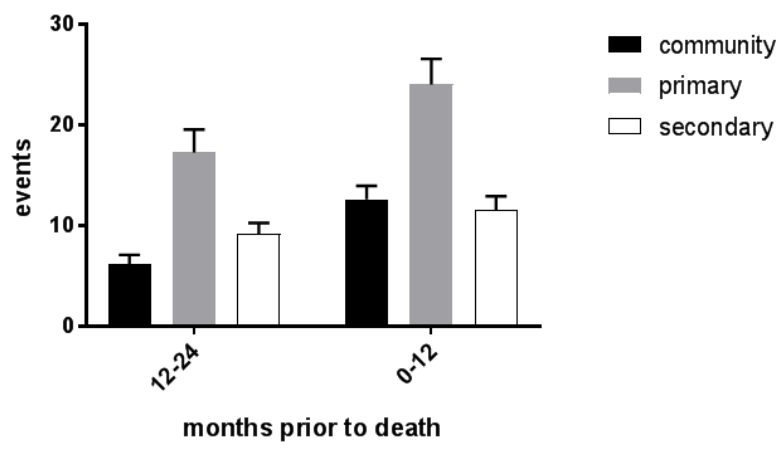

Figure 2 Type and number of clinical encounters prior to death for people with Parkinson's disease.

(12.47 $(6.748,18.18), \mathrm{p}<0.0001)$. We observed that the number of clinical encounters was not associated with non-hospital deaths (two-way repeated measures ANOVA, $F(1,58)=1.001, \mathrm{p}=0.321)$, nor with dying in a nursing home (two-way repeated measures ANOVA, $F(1,58)=1.001, \mathrm{p}=0.289)$.

\section{Individual factors related to ACP, recognition of dying and location of death}

Since we were unable to identify factors that influenced hospital death based on factors associated with the person's 'illness' and their 'individual' factors or the characteristics of their caregivers, we investigated the impact of ACP. To achieve this, we also incorporated the controls to permit us to understand in more detail the impact of having a long-term condition. Based on the number of controls available, we extracted specific details on ACP and recognition of dying. This resulted in 136 people with MS, 96 people with PD and 95 controls. We observed the frequency of ACP and recognition of dying were higher among people with PD compared with controls and people with MS (table 2). A multivariate analysis of all three

Table 2 Presence of advance care plans and recognition of dying among controls, multiple sclerosis and Parkinson's disease

\begin{tabular}{llll}
\hline & $\begin{array}{l}\text { Control } \\
\text { population } \\
(\mathrm{n}=95) \\
\mathrm{n}(\%)\end{array}$ & $\begin{array}{l}\text { Multiple } \\
\text { sclerosis } \\
(\mathrm{n}=136) \\
\mathrm{n}(\%)\end{array}$ & $\begin{array}{l}\text { Parkinson's } \\
\text { disease }(\mathrm{n}=96) \\
\mathrm{n}(\%)\end{array}$ \\
\hline $\begin{array}{l}\text { Advance care } \\
\text { planning }\end{array}$ & $45(47.4)$ & $70(51.5)$ & $69(71.9)^{*} \dagger$ \\
$\begin{array}{l}\text { Recognition of } \\
\text { dying }\end{array}$ & $49(51.5)$ & $74(54.4)$ & $66(68.8) \neq \S$ \\
\hline
\end{tabular}

${ }^{*}$ Advance care plans: Parkinson's disease versus MS, $\chi^{2}=9.76$, $\mathrm{p}=0.0018$

†Advance care plans: Parkinson's disease versus controls, $\chi^{2}=11.92$, $\mathrm{p}=0.00056$.

‡Recognition of dying: Parkinson's disease versus MS, $\chi^{2}=4.83$, $\mathrm{p}=0.028$.

$\S$ Recognition of dying: Parkinson's disease versus controls, $\chi^{2}=5.88$, $\mathrm{p}=0.01$.

MS, multiple sclerosis. patient groups using the following variables-age, sex, disease trajectory, year of death, recognition of dying and possessing an advance care plan-was performed examining two outcomes-dying in hospital and dying at home. We identified that possessing an ACP (0.710 (0.623, 0.809), $\left.\mathrm{p}=4.36 \times 10^{-07}\right)$, recognition of dying $\left(0.708(0.623,0.9995), \mathrm{p}=1.94 \times 10^{-07}\right)$ and an earlier year of death $(1.011(1.002,1.021), \mathrm{p}=0.017)$ were associated with not dying in hospital $(F: 60.14$ on 3 and $307 \mathrm{df}$, adjusted $\mathrm{R}^{2}$ : $\left.0.364, \mathrm{p}<2.2 \times 10^{-16}\right)$. In contrast, factors associated with not dying at home (adjusted $\mathrm{R}^{2}: 0.07258, F$-statistic: 7.006 on 4 and 303 df, $\left.\mathrm{p}=2.092 \times 10^{-05}\right)$ included not possessing an ACP $(1.215(1.107,1.335))$ and not having a long-term neurological condition (PD $0.873(0.773,0.986)$; MS $0.805(0.711,0.912))$.

Individual (personal) factors related to ACP and recognition a person is dying

Given the place of ACP and recognition of dying in influencing hospital death, where details were available in clinical notes, we identified which individuals had an ACP discussion, who exactly put the ACP into place and who recognised the person was dying. GPs and/ or the GP and the patient's family were grouped, with the alternatives including community, family, hospital, hospice, nursing home or the patients themselves.

Overall, ACPs that were put in place by GPs and/ or the GP and patient's family resulted in significantly fewer hospital deaths, where only eight of the 91 cases were identified as dying in hospital. This compared with 54 of the 76 cases where ACPs were put in places by other HCPs $\left(\chi^{2}=68.77, p<0.0001\right)$ (table 3). Significantly more (44/67) (65.7\%) ACPs were put in place more often by GPs/and the patient's family among those with PD compared with controls $\left(\chi^{2}=4.92, p=0.027\right)$ and marginally more than among those with MS $\left(\chi^{2}=3.65, \mathrm{p}=0.056\right)$. Consequently, it appears that among people with PD, ACPs are more common and more effective in preventing hospital deaths.

Recognition of dying was again most frequently identified by GPs or GP and the patient's family. Furthermore, it was associated with non-hospital deaths. Specifically, 5 of the 96 people with PD who died in hospital were identified by the GP and/or the GP and the patient's family versus 44 of the 64 among those who were not identified by the GP or the GP and the patient's family $\left(\chi^{2}=72.97, p<0.0001\right)$. However, we did not identify an increase in rates of identification of recognition of dying in any of the conditions by the GP and/or the GP and the patient's family (table 3).

\section{Timing of ACP and location of death}

We also examined the length of time before death that an advance care plan was put in place and when a person was recognised as dying in the different diseases (MS, PD and controls) but also where a person eventually died (table 4). 
Table 3 Groups either initiating conversations about advance care plans and recognising a person with MS or PD was dying compared with controls

\begin{tabular}{|c|c|c|c|c|c|c|c|}
\hline & $\begin{array}{l}\text { Community } \\
\mathrm{n}(\%)\end{array}$ & $\begin{array}{l}\text { Family } \\
\mathrm{n}(\%)\end{array}$ & $\begin{array}{l}\text { GP or GP and family } \\
\mathrm{n}(\%)\end{array}$ & $\begin{array}{l}\text { Hospital } \\
\mathrm{n}(\%)\end{array}$ & $\begin{array}{l}\text { Nursing home } \\
\mathrm{n}(\%)\end{array}$ & $\begin{array}{l}\text { Hospice } \\
\mathrm{n}(\%)\end{array}$ & $\begin{array}{l}\text { Patient } \\
\mathrm{n}(\%)\end{array}$ \\
\hline \multicolumn{8}{|l|}{ Advance care planning } \\
\hline Control population $(n=44)$ & $3(6.8)$ & $3(6.8)$ & $17(38.6)$ & $4(9.1)$ & - & - & $17(38.6)$ \\
\hline Parkinson's disease $(n=67)$ & $4(6.0)$ & $5(7.5)$ & $44(65.7)$ & $9(13.4)$ & $3(4.5)$ & - & $2(3.0)$ \\
\hline Multiple sclerosis (n=65) & $4(6.2)$ & $6(9.2)$ & $32(49.2)$ & $7(10.8)$ & $1(1.5)$ & $3(4.6)$ & $12(18.5)$ \\
\hline \multicolumn{8}{|l|}{ Recognition of dying } \\
\hline Control population $(n=45)$ & $10(22.2)$ & $2(4.4)$ & $24(53.3)$ & $6(13.3)$ & - & $3(6.7)$ & - \\
\hline Parkinson's disease $(n=62)$ & $7(11.3)$ & - & $38(61.3)$ & $9(14.5)$ & $8(12.9)$ & - & - \\
\hline Multiple sclerosis $(n=53)$ & $1(1.9)$ & $2(3.8)$ & $34(64.2)$ & $7(13.2)$ & $6(11.3)$ & $3(5.7)$ & - \\
\hline
\end{tabular}

GP, general practitioner; MS, multiple sclerosis; PD, Parkinson's disease.

The timing of ACP occurred significantly earlier among those with MS compared with controls or those with PD (Kruskal-Wallis statistic $=19.77, \mathrm{p}<0.0001$, Dunn's multiple comparisons $\mathrm{p}<0.0006$ vs controls and those with PD). However, we did not identify how long before death dying was recognised among controls, those with MS or those with PD (Kruskal-Wallis statistic $=0.3336$, $\mathrm{p}=0.846$ ).

We found that although an advance care plan was in place for a longer period for those who died in hospital, it was not a significant factor compared with those who experienced a non-hospital death (Kolmogorov-Smirnov $\mathrm{D}=0.1797, \mathrm{p}=0.313$ ). However, in contrast, an advance care plan was in place significantly closer to death among those who experienced a home death versus those who died outside their home (Kolmogorov-Smirnov $\mathrm{D}=0.2384, \mathrm{p}=0.029$ ).

\section{DISCUSSION}

Chronic neurological conditions including PD and MS are typically characterised by progressive dwindling in neurological function over time and associated and increasing dependence. ${ }^{7}$ In the absence of a cure, highquality palliative care including the presence of ACP has been recommended as a key strategy intended to serve patients and their families to achieve quality of life and their preferences in the location of care and death. $^{262930}$

We confirm in a community-based population that the rate of death in hospital among those with MS was higher than those with PD, a finding supported by others. ${ }^{9}$ In an attempt to understand the basis of this difference we examined three key theoretical factors postulated by Gomes and Higginson ${ }^{11}$ - the individual's illness, the circumstances associated with the individual and their environment including use of health services-were associated with location of death. In our analysis, we were not able to confirm that the disease-related factor was significant, despite there being differences between MS and PD concerning patients' clinical characteristics. This is despite the patient's age at death and gender contributing to this effect, although in a small way.

When examining environmental factors, we catalogued all contacts with health service providers in a subgroup analysis of people with MS and people with PD. Despite identifying increases in service-related activity with patients increasing

Table 4 The length of time (days) prior to death an ACP put in place and when person recognised as dying by disease type versus controls and location of death

\begin{tabular}{|c|c|c|c|c|c|c|}
\hline & \multicolumn{3}{|c|}{ Advance care plan in place (days) } & \multicolumn{3}{|c|}{ Recognition of dying (days) } \\
\hline & $\mathrm{n}$ & Mean \pm SD & Median (range) & $\mathrm{n}$ & Mean \pm SD & Median (range) \\
\hline \multicolumn{7}{|l|}{ By disease type } \\
\hline Control population & 42 & $123.1 \pm 339.7$ & $17(0-2095)$ & 47 & $20.5 \pm 52.8$ & $9(0-365)$ \\
\hline Parkinson's disease & 67 & $118.6 \pm 222.2$ & $15(0-1009)$ & 64 & $22.8 \pm 50.6$ & $9(0-378)$ \\
\hline Multiple sclerosis & 70 & $345.5 \pm 648.1$ & $119(1-3928)$ & 74 & $35.5 \pm 135.3$ & $10(0-1151)$ \\
\hline \multicolumn{7}{|l|}{ Died in hospital } \\
\hline Yes & 36 & $417.6 \pm 887.8$ & $69.5(2-3928)$ & 38 & $24.3 \pm 41.1$ & $9(0-221)$ \\
\hline No & 142 & $152.5 \pm 257.8$ & $30(0-1503)$ & 147 & $28.1 \pm 103.7$ & $8(0-1151)$ \\
\hline \multicolumn{7}{|l|}{ Died at home } \\
\hline Yes & 53 & $122.9 \pm 253.3$ & $16(0-1503)$ & 55 & $10.7+9.5$ & $8(0-43)$ \\
\hline No & 125 & $241.5 \pm 532.2$ & $49(0-3928)$ & 130 & $34.3+111.6$ & $10.5(0-1151)$ \\
\hline
\end{tabular}

$\mathrm{ACP}$, advance care planning. 
dependency, we were unable to identify that the presence of increasing services contributed to dying at home or in a hospice. This finding may be a consequence of how community care is now delivered, with care being more focused on specific elements of care where it is difficult to identify an overall change health status of patient and associated outcomes. ${ }^{31}$

However, in terms of individual factors, our subgroup analysis identified that possessing an advance care plan significantly contributed to realising preferred place of death. This was typically at home, the most preferred location for dying. ${ }^{2-4}$ It is here we identified that ACP can be viewed as an important independent factor associated with realising patients' preferences and specifically achieving non-hospital deaths, a role supported by the UK's 2021 national policy document 'Ambitions for Palliative and End of Life Care'. ${ }^{16}$

Using patient-linked clinical records to gain a more detailed insight into the specific types of clinical encounters patients experienced in the months leading up to their death, we identified that the patients' GP represented a key factor in initiating timely and potentially difficult conversations about ACP. This finding supports a recent realist review of the imperative for health professionals to engage with people with MS in the ACP process at the most opportune moment and that health professional be considered by the person with MS to have trusting and empathic qualities. ${ }^{26}$ In addition, GPs were shown to subsequently take a role in coordinating future patient care together with their family and were instrumental in contributing to making it possible for that care to take place in a location of the patient's preference to prevent hospital deaths. This finding cannot be underestimated, particularly given that these instances of conversations and subsequent care were more frequent than among patients where ACP discussions were initiated by other HCPs. GPs have similarly been identified as the key health professional as initiating conversations about ACP with people living with dementia and their families. ${ }^{32}$ In Scotland, anticipatory care plans form part of 'Key Information Summary' implemented by GPs as part of their contract and they have been effective in reducing hospital deaths when they are introduced at a median of 105 days before death. However, unlike our findings they were not able to compare the efficacy of implementation by GPs when compared with by other HCPs. $^{10}$

Finally, we explain the difference in hospital death rates in MS and PD through the fact that people with PD have more ACPs implemented by primary care who may be more effective at delivering this desired outcome.

\section{Study limitations}

This study has limitations that affect the inferences of the findings presented. First, there is a potential bias in the populations sampled since they voluntarily chose to become part of the UK MS PD TB. However, we have previously shown in terms of MS this population is reflective of a general MS population. ${ }^{28} \mathrm{~A}$ similar formal comparison for those with PD has yet to take place. As with any retrospective study, we may have missed some patient records, most likely with the move towards electronic record keeping.

\section{CONCLUSIONS}

From a clinical and public health perspective, a focus on examining which factors contribute to making home death possible is important and timely, given that hospital utilisation rises exponentially towards death, a trend that is projected to continue. ${ }^{4}$ Moreover, place of death has both societal and economic implications. ${ }^{133} 34$ Improving end-of-life care that may include the development and enactment of $\mathrm{ACP}$ is an ongoing public health priority in many countries globally and has received greater attention during the COVID-19 pandemic. $^{23}{ }^{24}$ In this analysis, we have shown that ACP, when delivered by primary care practitioners with patients and their families, is associated with lower levels of hospital death and commensurately more home deaths, the latter generally considered to be a marker of quality of end-of-life care. ${ }^{35}$ We also demonstrate that professionals working in primary care are also effective in recognising the final phase of a person's life which counters some claims that prognosis is challenging and imprecise, particularly for those with non-malignant conditions. ${ }^{36-38}$ This has implications for facilitating discussions with people living with progressive neurological diseases and their families that potentially empower and enable them to make decisions about current and future care that maximise their quality of life. Our findings compel any initiative aimed at enabling people with neurological illnesses who express a desire to remain at home to respond adequately to all factors we identify in this study and also consider the contribution of ACP and the conditions required to make it relevant and acceptable to those who might benefit from it. ${ }^{26}$

\section{Author affiliations \\ ${ }^{1}$ UK Multiple Sclerosis Tissue Bank, Imperial College London, London, UK ${ }^{2}$ Department of Medical Statistics, University Medical Center, University of Göttingen, Göttingen, Germany \\ ${ }^{3}$ Department of Palliative Care, Policy and Rehabiltation, Florence Nightingale Faculty of Nursing, Midwifery and Palliative Care, King's College London, London, UK}

TwitterTim Friede@tim_friede and Jonathan Koffman@ jonathankoffman

Contributors All authors made substantial contributions to the conception and design of the work. EN and RN facilitated the acquisition of data. MH led the analysis of data. JK and RN 
drafted the paper. All authors read, revised and approved the final version of the manuscript.

Funding The UK MS Society and Parkinson's UK jointly funded the UK MS and PD Tissue Bank at Imperial College.

Competing interests None declared.

Patient consent for publication Not required.

Ethics approval The Multiple Sclerosis Society Tissue Bank at Imperial College London has been approved as a research tissue bank by the Wales Research Ethics Committee (reference number 08/mre09/31+5) and this project was further approved by the UK MS PD TB subcommittee.

Provenance and peer review Not commissioned; externally peer reviewed.

Data availability statement Data generated by this research that supports this article will be be made openly and publicly available upon request.

Open access This is an open access article distributed in accordance with the Creative Commons Attribution Non Commercial (CC BY-NC 4.0) license, which permits others to distribute, remix, adapt, build upon this work noncommercially, and license their derivative works on different terms, provided the original work is properly cited, appropriate credit is given, any changes made indicated, and the use is noncommercial. See: http://creativecommons.org/licenses/by-nc/4. $0 /$.

\section{ORCID iDs}

Tim Friede http://orcid.org/0000-0001-5347-7441

Jonathan Koffman http://orcid.org/0000-0001-8513-5681

\section{REFERENCES}

1 Gomes B, Calanzani N, Koffman J, et al. Is dying in hospital better than home in incurable cancer and what factors influence this? a population-based study. BMC Med 2015; $13: 235$.

2 Hoare S, Morris ZS, Kelly MP, et al. Do patients want to die at home? A systematic review of the UK literature, focused on missing preferences for place of death. PLoS One 2015; 10:e0142723.

3 Gomes B, Calanzani N, Gysels M, et al. Heterogeneity and changes in preferences for dying at home: a systematic review. BMC Palliat Care 2013;12:7.

4 Bone AE, Gomes B, Etkind SN, et al. What is the impact of population ageing on the future provision of end-of-life care? population-based projections of place of death. Palliat Med 2018;32:329-36.

5 Golla H, Fink G, Rolke R, et al. New structures in neurology: palliative care for neurological patients. Neurology International Open 2017;01:E117-26.

6 Lunney JR, Lynn J, Foley DJ, et al. Patterns of functional decline at the end of life. JAMA 2003;289:2387-92.

7 Martin JE, Raffel J, Nicholas R. Progressive Dwindling in multiple sclerosis: an opportunity to improve care. PLoS One 2016;11:e0159210.

8 National Neurology Intelligence Network National End of Life Care Intelligence Network. Deaths associated with neurological conditions in England 2001 to 2014: data analysis report. 40. London: Public Health England, 2018.

9 Sleeman KE, Ho YK, Verne J, et al. Place of death, and its relation with underlying cause of death, in Parkinson's disease, motor neurone disease, and multiple sclerosis: A populationbased study. Palliat Med 2013;27:840-6.

10 Darweesh SKL, Raphael KG, Brundin P, et al. Parkinson matters. J Parkinsons Dis 2018;8:495-8.

11 Gomes B, Higginson IJ. Factors influencing death at home in terminally ill patients with cancer: systematic review. BMJ 2006;332:515-21.
12 Brinkman-Stoppelenburg A, Rietjens JAC, van der Heide A. The effects of advance care planning on end-of-life care: a systematic review. Palliat Med 2014;28:1000-25.

13 Song K, Amatya B, Voutier C, et al. Advance care planning in patients with primary malignant brain tumors: a systematic review. Front Oncol 2016;6:223.

14 Detering KM, Hancock AD, Reade MC, et al. The impact of advance care planning on end of life care in elderly patients: randomised controlled trial. BMJ 2010;340:c1345.

15 Rietjens JAC, Sudore RL, Connolly M, et al. Definition and recommendations for advance care planning: an international consensus supported by the European association for palliative care. Lancet Oncol 2017;18:e543-51.

16 National Palliative and End of Life Care Partnership. Ambitions for palliative and end of life care: a national framework for local action 2021-2026, 2021: 50.

17 Korfage IJ, Carreras G, Arnfeldt Christensen CM, et al. Advance care planning in patients with advanced cancer: a 6-country, cluster-randomised clinical trial. PLoS Med 2020;17:e1003422.

18 Block BL, Jeon SY, Sudore RL, et al. Patterns and trends in advance care planning among older adults who received intensive care at the end of life. JAMA Intern Med 2020;180:786-9.

19 Ruseckaite R, Detering KM, Evans SM, et al. Protocol for a national prevalence study of advance care planning documentation and self-reported uptake in Australia. BMJ Open 2017;7:e018024.

20 Lin C-P, Evans CJ, Koffman J, et al. Feasibility and acceptability of a culturally adapted advance care planning intervention for people living with advanced cancer and their families: a mixed methods study. Palliat Med 2020;34:651-66.

21 Abel J, Pring A, Rich A, et al. The impact of advance care planning of place of death, a hospice retrospective cohort study. BMJ Support Palliat Care 2013;3:168-73.

22 Bond WF, Kim M, Franciskovich CM, et al. Advance care planning in an accountable care organization is associated with increased advanced directive documentation and decreased costs. J Palliat Med 2018;21:489-502.

23 Block BL, Smith AK, Sudore RL. During COVID-19, outpatient advance care planning is imperative: we need all hands on Deck. J Am Geriatr Soc 2020;68:1395-7.

24 Curtis JR, Kross EK, Stapleton RD. The importance of addressing advance care planning and decisions about do-notresuscitate orders during novel coronavirus 2019 (COVID-19). JAMA 2020;323:1771-2.

25 Bradshaw A, Bayly J, Penfold C, et al. Comment on: "Advance" care planning reenvisioned. J Am Geriatr Soc 2021;69:1177-9.

26 Cottrell L, Economos G, Evans C, et al. A realist review of advance care planning for people with multiple sclerosis and their families. PLoS One 2020;15:e0240815.

27 Imperial College London. Multiple Sclerosis and Parkinson's Tissue Bank London: Imperial College London 2019 [cited 9 Sep 2019]. Available: https://www.imperial.ac.uk/medicine/ multiple-sclerosis-and-parkinsons-tissue-bank [Accessed 9 Sep 2019].

28 Reynolds R, Roncaroli F, Nicholas R, et al. The neuropathological basis of clinical progression in multiple sclerosis. Acta Neuropathol 2011;122:155-70.

29 Grimes D, Gordon J, Snelgrove B, et al. Canadian guidelines on Parkinson's disease. Can J Neurol Sci 2012;39:S1-30.

30 Gao W, Wilson R, Hepgul N, et al. Effect of short-term integrated palliative care on patient-reported outcomes among patients severely affected with long-term neurological conditions: a randomized clinical trial. JAMA Netw Open 2020;3:e2015061-e61.

31 Charles A, Ham C, Baird B. Reimagining community services: making the most of our assets. 118. London: The KIng's Fund, 2018. 
32 Bally KW, Krones T, Jox RJ. Advance care planning for people with dementia: the role of general practitioners. Gerontology 2020;66:40-6.

33 May P, Normand C, Cassel JB, et al. Economics of palliative care for hospitalized adults with serious illness: a meta-analysis. JAMA Intern Med 2018;178:820-9.

34 May P, Morrison RS, Murtagh FE. Current state of the economics of palliative and end-of-life care: a clinical view. Palliat Med 2017;31:293-5.

35 Henson LA, Edmonds P, Johnston A, et al. Population-Based quality indicators for end-of-life cancer care: a systematic review. JAMA Oncol 2020;6:142-50.
36 Nutter AL, Tanawuttiwat T, Silver MA. Evaluation of 6 prognostic models used to calculate mortality rates in elderly heart failure patients with a fatal heart failure admission. Congest Heart Fail 2010;16:196-201.

37 Glimelius B. Palliative medicine--a research challenge. Acta Oncol 2000;39:891-3.

38 Koffman J, Yorganci E, Yi D, et al. Managing uncertain recovery for patients nearing the end of life in hospital: a mixed-methods feasibility cluster randomised controlled trial of the amber care bundle. Trials 2019;20:506. 